\title{
Sexual Objectification of Pinoy Males in Billboard Advertisements
}

\author{
Marc Agon Pacoma ${ }^{1, *}$ \\ ${ }^{1}$ Department of Communication - Adamson University, Manila, Philippines
}

\begin{abstract}
Male models in skimpy undergarments showing their Adonislike physique, presented in sexualized poses with disturbing bulges or crotches is one of the common landscapes in the Philippine advertising today. The author found the conflicting idea of a nation rich in morals, values and principles but endure high profanity or obscenity through sexualized male bodies as seen in billboards of fashion brands and gratification of visual desire among its spectators. Advertising promotes this phenomenon stimulating the idea that sex truly sells, male models are objectified as sexual objects capturing consumers' attention resulting to persuasion and eventual consumption of the product. Ads showing Pinoy males' chiselled bodies in silhouettes communicating sexual innuendos constitute a contemporary marketing technique; a ploy for companies to earn profit yet an avenue for public scrutiny and moral outcry.
\end{abstract}

\section{Introduction}

Advertising is a marketplace of ideas normally transferred through various media platforms, with the goal of communicating distinct characteristics of products and services among consumers [1]. Furthermore, it helps companies and brands build their identities thus, being recognized and recalled among its target audiences [2]. Presently, numerous types of advertising are evident [3] employing various techniques in order to earn profits or revenues, as advertisers continuously face difficulties in terms of sending across the messages about their products [4]. With this, most of them resorted to numerous marketing techniques and tactics. One of the most pervasive advertising practices is displaying the images of gender as part of products which typically draw in consumers' attentions, resulting to sales and earnings among brands and companies that exploit this marketing style.

This paper focuses on Bench Body's strategy of promoting its undergarment products through billboard advertisements. Specifically, it describes how Bench as a company utilizes images of male models to attract attention of heterosexual consumers, resulting to persuasion and possible product consumption. The paper argues that men just like women experiences commodification or objectification, portraying them as sexualized individuals or objects of sexual desires and fulfilment. It further delves into the idea that men same with its feminine counterpart experiences negative portrayals or representations in various

*Corresponding author: marckiepacoma@yahoo.com. 
media platforms. Also, the paper describes how male models are presented in these billboard ads and how Bench pleasures out from this marketing ploy. Using the Cultural Studies of Stuart Hall, the researcher seeks to answer the subliminal messages or interpretations presented in the billboard advertisements.

Bench Body is the focus of the paper due to its current position as the market leader in the Philippine undergarments and the pioneer in the undergarment billboard advertising. Since its inception, it produces roughly 100 billboards in various themes and concepts, featuring local and international-renowned models and celebrities. This move make them a top choice among Filipino consumers, posting roughly P2 billion in sales, way ahead of its closest apparel competitor, Penshoppe [5]. The figures imply that consumers are into enormous patronage and high consumption of Bench and Bench Body's merchandises, which makes it ideal to investigate. But what makes it more worthy of scrutiny is its constant usage of male models who are sexually-posed and sparsely-dressed with provocative captions or headlines in its outdoor advertising. With this, the study was conjured in an attempt to examine the sexual objectification of Filipino males in billboard advertisements of Bench Body. More so, it seeks to describe how these billboard advertisements are sexualized in nature and present the elements that make them bearers of male commodification.

\section{Sexual Objectification: a contemporary advertising technique}

The quest in finding the perfect way to reach the right consumers seemed to be evasive. New advertising strategies came to light in order to cater the various potential customers [6]. Portrayals of gender thrived in media and considered to be the most prevalent one. This new way of selling is characterized by images of men and women appearing side by side with the product; performing less professional and subordinate social roles; showing highly sexualized poses or depicting demeaning stances. The proliferation of this visual rhetoric led to the enormous interests in research among consumer and communication researchers, gender experts and even academic institutions. Using sex to sell is a concept which was not conceived in just one day, this has been the philosophy that many advertisers and marketers embrace to market their products which was popularized by international brands like Calvin and Klein, Abercrombie \& Fitch, Carl's Junior [7], Levis and Candies [8].

The proliferation of sexual information incorporated in advertisements proliferated in the 1960's with sex almost synonymous to nudity and other sexual information [9]. But the popularity of this technique can be traced back in the 1850s, when images of sex and gratification were utilized to sell various products and services [10]. Undeniably, the exploitation of human bodies in advertisements seemed to be a flesh-selling market or a syndicate of sex. Sexual information in advertising are presented in various forms of physical desirability, clothing and body exposure, sexual comportment, sexual interpretations and undertones [9]. Visual displays of human bodies both of men and women seemed to be a part of the pop culture [11]. Much have been investigated on the female, their bodies and representations but with less interest on its counterpart - the males.

Inquiries surrounding men are few since most researchers are focused on the subordinate and submissive, women. Many thought subsequently that masculinity does not encounter any gender issues because of its position in the society but its current condition as a tool in marketing does not make it exempted when it comes to evaluation of gender portrayals. What makes it more disturbing is that men appeared side by side the products or services being marketed: vulnerable, provocative and sexually objectified - demonstrating a masculinity in crisis. Sexual objectification is perceiving an individual as objects of erotic desire [12], focusing mainly on sexual and physical appeals [13]. It has been a staple topic among researchers, equally investigating the portrayal of men and women in various media 
platforms such as television, film, and print media among others. This is most commonly associated with femininity however imposes a serious threat on the masculine gender. Arguably, masculinity can be represented by either bodies or physical appearance [14], leading to the concept of objectification and sexualization [15]. Indeed, images of men started to flourish; appearing in printed and outdoor advertising such as but not limited to newspapers, posters, magazines and billboards.

\section{Sexualized billboard advertising in the Philippines}

Billboards are large structures usually situated for advertising purposes [16]. It is one of the most preferred categories among out of home advertising due to its ability to reach quickly its targeted audiences in certain locations [17]. The Philippines specifically Metro Manila is a hub for outdoor advertising, with roughly thousands of billboards situated in its various thoroughfares, making it one of the most visually distracting cities in Southeast Asia. But the proliferation of these advertising type is extremely distressing not just because of their large physical structures but its controversial and provocative contents resulting to moral outcry and criticisms among public, the government and ethical groups [18].

The emergence of male bodies as a marketing ploy is extremely visible in different billboards of products and services (perfumes, beverages, gadgets and fashion brands). One of the companies that resorted to this type of promotional technique is Bench which is owned by the Filipino-Chinese fashion business mogul, Mr. Ben Chan. Bench had pioneered in the country the incorporation of male models presented in highly provocative poses wearing skimpy or scantily-clad clothing with risqué captions and headings. Issues of sexual overtones and morality had stimulated the general public and deliberately outraging various sectors.

Among the other controversial outdoor advertisements that were criticized for its indecent images, sexual insinuations and erotic symbolisms are: Napoleon Quince's "Nakatikim ka na ba ng Kinse Anyos?" [Have you tasted a 15 year old?], Bayantel's Satisfaction Guarantee and Bench's underwear ads among others. These raunchy ads incorporate sex in its marketing formula making them disturbing and scandalous [19]. Of all these ads, Bench seemed to be the top notch in sexualizing gender imageries resulting to a market lead in the Philippine fashion brand industry. Bench's unceasing success was palpable on its massive, thought-provoking, and sensualized billboard advertisements that continuously strike the attention of every Filipino consumers.

\section{Bench billboards and the realms of sexualized underwear ads}

Bench is a Filipino global brand that started in 1987 as a single shirt outlet and later on had its reach in other countries like China, the Middle East [20], Singapore and even in the United States of America. From its humble roots, the company grew steadily fast; offering a wide array of clothing for men and women. Sooner, it ventured out to the field of beauty through its Bench Fix Salon bringing in hair and grooming products to Pinoy clientele. But to further its market lead, Bench overhauled its underclothing goods through its Bench Body, offering sleek, sexy, and trendy undergarments for both sexes.

With the Bench Body's reinvention, came a frantic move to maintain the lead by showcasing sensual men and women. Both presented in highly sexual poses with skimpy and scantily clothes, exposing some skin and body parts. But what makes it more divisive are humungous and imposing images of men in sexualized poses communicating sexual innuendos, wearing see-through clothes or silhouettes with their chiseled bodies [21] and crotch bulges noticeable from public's eyes. Bench Body's male models are often seen in a 
situation where one's masculinity should be ripped off in order to increase the sale of the undergarments. This was apparent in some of their billboard advertisements where goodlooking guys show off their greased-muscular bodies wearing themed-costume from top Philippine fashion designers matching their scanty silhouette bikini briefs.

Nonetheless, this is not always the case, just like the billboard ads of the National Rugby Team of the Philippines (Philippine Volcanoes), which aims to promote rugby as a sport among Filipinos and raise funds for the team as they compete in various international competitions [22]. Philippine Volcanoes members posed individually and collectively but just like the common marketing ploy of Bench Body - where models wear measly undies showcasing their bodies and private parts as mere focal points of the ads; the photoshoots didn't fare well with the Filipinos, making these billboards a national issue with specific slants on morality and religion. It became a topic among debates and public outcry questioning its revealing sexual male imageries in too provocative poses. Others question the geographical locations of these out-of-home ads, as they were situated along a national road which may distract the focus and attention of daily commuters [23]. The Philippine Volcanoes' ad became a hit as everyone had their fair share of the issue, may it be in the academe, legislation, religious and moral sectors; lambasting the decency of the images presented and questioning the ethical standards of advertising in the country.

\section{Emergence of sexualized billboard ads: a violation of Philippine advertising regulations}

The themes of Bench Body billboard ads vary but the technique of presenting the product remains the same employing sexism or sexualization which makes it more appealing and sellable among Filipino consumers. This marketing ploy is indeed a violation of various Philippine advertising regulations as stressed in the Advertising Board of the Philippines (AdBoard) in its Advertising Code of Ethics (2000) [24] Article IV Section 1, where it is stressed that the presentation of human subjects in varied advertising forms should not be highly sexualized, vulgar, obscene and exploitative. Furthermore, Article IX stressed that, partly nude person is not allowed under the circumstances of: dressed in rickety or silhouette garments and dressed in skimpy or scantily-clad clothing exposing too much skin [female's body contours and male's bulging virilities].

But with the dissolution of the Ad Board, the Ad Standards Council (ASC) finally took over the role as the ultimate authority in the implementation of regulations surrounding ad contents [25]. Nevertheless, Bench Body's billboard ads are still in violation with the ASC's Revised Code of Ethics (2011) specifically its Article 1 [General Standards of Presentation] under Section 4 [Sex, Profanity, Obscenity and Vulgarity] provision where high profanity and extremely obscene advertising materials are prohibited. The employment of male models scarcely-dressed with Adonis-like physique and disturbing crotches, compromises these provisions. Particularly, Bench Body's billboard ads are presented in offensive nature and somehow contravene social and ethical standards. Moreover, these ads utilized obscene and vulgar poses, facial expressions, erotic situations, sensual props and setting and salacious taglines; suggesting sex as a way of selling the products. In addition, human subjects are deemed as sexual objects presented in stereotypical and violent themes, creating provocative presentations of sexual organs. Additionally, male subjects in the ads are displayed in critical poses simulating sexual intercourses and appeared in evocative physical contacts. Bench Body's billboard ads portray sexual acts and inhibitions which promote exploitative sexual tones that are of violation to Philippine society's morality standards. 


\section{Theoretical framework}

This study is guided by the Reception Studies or popularly known as the Cultural Studies of Stuart Hall. The theory mainly discusses how audiences associate and interpret different media contents. Specifically, the study is anchored by the three media concepts of the theory: dominant reading, negotiated meaning and oppositional decoding. Dominant reading refers to the preferred meanings or interpretations that the producer of the message has for the content. Negotiated meaning on the other hand, pertains to somehow similar interpretation to the actual meaning of media texts but contests its philosophy and application while oppositional decoding literally means opposite association of meaning which is directly contradictory to those of the dominant and negotiated interpretations [2629]. Also, the study is anchored on Suzanne Moore's Female Gaze Theory (1988) [30]. It argues that there is a female gaze in media which is far different from the male gaze. Furthermore, the theory explains that portrayals of men are patterned on traditional female representations such as nudity, scantily-clothed, sexual stares and sensual innuendos. Additionally, it stressed that this type of gaze is evident on the influx of male imageries in film and advertising.

The application of the concepts of Cultural Studies is focused on the interpretations or associations attached to the various billboard advertisements if they conform or compromise Bench Body's purpose of promoting the brand and its products. If these ads coincide with the brand's intention then they stand in dominant reading. But when these ads are in total opposite (demoralizing the image of the brand or downplaying its credibility) of the intentions of the undergarment brand then it is in oppositional reading. Negotiated reading is when these billboard advertisements concur with the preferred meaning (promotion of Bench Body's undergarments) but opposes its application (presence of sexualized male models or depiction of sexual objectification in the billboard ads). Female Gaze Theory on the other hand, explicated the idea that men same with its feminine counterpart can be subjected to sexual commodification in different parameters such as eye contact, posture, clothing and body language.

\section{Methods}

The study employed a qualitative approach since its goal is to describe the phenomenon of the emergence of sexualized male models in billboard advertisements. Furthermore, the study aims to determine the elements and the process involve in evaluating sexual objectification in the said out-of-home advertising. Specifically, content analysis is utilized which allowed the researcher to quantify the categories of various advertisements [33].

The researcher collected all possible materials for the study and a criteria was placed to filter the billboard ads to be used. Criteria in the selection of the ads are as follows: (1) should be a Bench Body billboard ad; (2) preferably under any Bench Body campaign; (3) could be in any theme or concept and (4) male model(s) in the ads should be Filipino [half breed or with Filipino blood]. After the selection process, the researcher came up with 27 billboard ads to analyze using a researcher-made coding sheet [based on various categories from previous literature and parameters presented in Visual Pleasure and Narrative Cinema (1975) [32] and Male Gaze (1975) [33]]. The coding sheet included various categories such as the theme of the billboard ad, underwear type and style, color, color intensity, gaze direction, gaze type, facial expression, body exposure, body type, body focus, body pose, advertising message and overall impression of the ad. The materials were examined, coded, classified and analyzed based on categories and occurrences, in order for the researcher to make inferences on their social and cultural contexts [34]. 


\section{Findings and analysis}

The samples were analyzed using various categories collated from previous researches and literature such as the theme, underwear type and style, color and intensity, gaze type and direction, facial expression, body type and focus, body exposure and pose, advertising message and the over-all presentation of the ad.

Content analysis revealed that the predominant theme of Bench Body billboard ads were sporty in nature, depicting male models posing with sports paraphernalia and equipment but there were also billboards with Victorian/Persian and Royalty themes. With regards to the underwear type and style, mostly bikini briefs that are low rise were used as main clothing of the male models. Scantily-clad or skimpy clothing constitute the idea of nudity [35], which is increasingly popular as an advertising technique. In terms of color and intensity, black and white seemed to be the top hue as shown through lighting and backgrounds of the advertisements. Most of the billboard ads looked dull and lack brightness and vividness, portraying a somber mood; allowing audiences to focus on the well-lighted parts of the billboard which are - the male bodies. In terms of gaze' types and directions, most models project a direct gaze to its audiences and predominantly are seductive or sensual in nature. Voyeuristic gaze implies a look towards the audience that is sexually arousing or objectifying towards same sex [36-37]. Facial expressions of the models were somehow mixed as some depict dominance, seduction and inviting vibes. With regards to body exposure and type, billboard ads displayed mostly whole bodies (head to knees) of the models and muscular bodies were usually the one strutting the various Bench Body billboards; exposing chiseled or hardly gym-ripped masculine physiques. This is a prototype of the New Man which is an eroticized representation of men often asserting certain body features, capturing audience attention $[38,15]$. When it comes to body focus and pose, ads were dominantly showcasing male models standing with crotches or bulges which are quite obvious and noticeable from the audience eyes

Most of the Bench Body billboard ads conveyed indirect or underlying advertising message, not just promoting the company's product but also presented the idea of sexual objectification through the utilization of sexual imageries. Advertising unconsciously present subliminal messages aside from obvious visual metaphors [37]. Billboard ads were primarily presented in sensual, provocative and sexually- arousing manner.

\section{Conclusions}

The analysis results indicated that the idea of sex sells or sexual objectifications are highly exploited by fashion industry in order to promote their products and gain profit and revenue. And this is true in the case of Bench that tries to employ numerous marketing ploys ranging from sexualized male models to risqué headlines or captions; resulting to public scrutiny and outcry among consumers and moralists. Thus, the images of male models in the Bench Body billboards represented Filipinos as confident human beings but are portrayed as sexual objects with handsome looks and Adonis-like physiques. Indeed, Bench Body exploit human bodies as marketing ploys, compromising the standards of morality, religion and ethics of Philippine society.

\section{Recommendations}

Philippine government concerned agencies must impose firm regulations on advertising and its various types, specifically on its contents, themes, imageries and presentations. Furthermore, Metropolitan Manila Development Authority (MMDA) and Department of 
Public Works and Highways (DPWH) must implement seriously the guidelines concerning placement of billboard advertisements in different public roads and thoroughfares as not to promote visual pollution and not to affect commuters' attention. Moreover, Ad Standard Council (ACS) and other advertising regulating bodies must be stricter in screening advertisements specifically its contents and implications to consumers. Additionally, advertising agencies and their creative think tankers should utilize human metaphors in lieu of actual human bodies. In addition, Bench and other fashion brands must resort to other advertising or promotional techniques or tactics in selling their products. These companies must retire from employing erotic and risqué models appearing side by side or incorporated with their products. For future research endeavors, the researcher recommends a holistic study dealing with all the billboard advertisements of Bench Body.

\section{References}

1. C. Chih-Chung, C. Chang, L. Wei-Chun Lin, Y. Nang, Procedia-Social and Behavioral Sciences, 57, 352-359 (2012)

2. S.M. Busen, C.S Mustaffa, Procedia-Social and Behavioral Sciences, 155, 98-103 (2014)

3. P. Elena, Procedia-Social and Behavioral Sciences, 76, 686-689 (2013)

4. M. Muda, R. Musa, R. N. Mohamed, H. Borhan, Procedia-Social and Behavioral Sciences, 130, 11-20 (2014)

5. GMA Network, retrieved from: http://www.gmanetwork.com/news/story/134812/money/penshoppe-bench-cite-strongsales-but-profits-likely-to-get-hit (2008, November 21)

6. J. Sivulka, Soap, Sex and Cigarettes: A Cultural History of American Advertising (2012)

7. J. Speck, A. Guierrez, J. Sawayda, Marketing Campaigns Use of Sex Appeal to Sell Products (2011)

8. P. M. Lester, Visual Communication: Images with Messages (2014)

9. T. Reichert, J. Lambiase, Sex in Advertising: Perspectives on the Erotic Appeal (2010)

10. T. Hayri, Procedia-Social Behavioral Sciences, 62, 1133-1137 (2012)

11. S.M. Alexander, Sociological Perspectives, 46 (4), 535-554 (2003)

12. M. Lövenberg, The Elven Slave and Conan the Barbarian: Male Sexualization in Video Games (2012)

13. J. Shewmaker, Sexualized Media Messages and Our Children: Teaching Kids to Be Smart Critics and Consumers (2015)

14. K. Milestone, A. Meyer, Gender and Popular Culture (2012)

15. S. Nixon, Hard Looks: Masculinities, Spectatorship and Contemporary Consumption (1996)

16. M. Dela Cueva, G. Gozar, C. Allingag, A. Salta, N. Enriquez, Southeast Asian Ergonomics Conference (2008)

17. E. B. Franch, C.B. Albiol, Online Journal of Communication and Media Technologies. 3 (2), 94-111 (2013)

18. J.E.A. Gomez Jr., The Billboardization of Metro Manila. Int. J. Urban Reg. Res. 37 (1), 186-214 (2013)

19. M.C. Hatol, Using Sex to Sell, retrieved from: http://www.mb.com.ph/using-sex-to-sell (2014, June 15)

20. Bench as a Global Brand, retrieved from : http://www.manilastandardtoday.com/lifestyle/107436/bench-as-a-global-brand.html (2013, June 25) 
21. Spot.PH, retrieved from: www.spot.ph/peopleparties/48710/philippine-volcanoessizzle-in-bench- billboards?ref=cxsearch\#photo-1370-1 (2011, June 30)

22. R. Gonzales, retrieved from: www.pep.ph/news/30082/national-rugby-team-philippinevolcanoes-pose- in-their-underwear-to-create-awareness (2011, July 6)

23. N. Almo, retrieved from: http://www.pep.ph/news/30109/mayor/requests-that-sexybillboards-of-national-rugby-team-philippine-volcanoes-betaken-down (2011, July 8)

24. AdBoard, retrieved from: www.scribd.com/doc/71448729/AdBoard-Advertising-Codeof-Ethics- Manual\#scribd (2000)

25. Ad Standard Council, retrieved from: www.asc.com.ph/our-standards/code-ofethics/general-standards- of-presentation (2016)

26. McQuail, Mass Communication Theory (2010)

27. S. Littlejohn, K. Foss, Encyclopedia of Communication Theory (2009)

28. S.J. Baran, D.K. Davis, Mass Communication Theory: Foundations, Ferment and Future (2012)

29. E. Griffin, A First Look at Communication Theory (2011)

30. L. Gamman, M. Marshment, The Female Gaze: Women as Viewers of Popular Culture (1989)

31. G. G. Sparks, Media Effects Research: A Basic Overview (2013)

32. L. Mulvey, Visual Pleasure and Narrative Cinema: Visual and Other Pleasures (1975)

33. D. Chandler, retrieved from: http://visual-memory.co.uk/daniel/Documents/gaze/gaze11.html (2014, July 7)

34. E. Pernia, Communication Research in the Philippines: Issues and Methods (2004)

35. C.R. Wiles, J. A. Wiles, A. Tjernlund, J ADVERTISING RES, 36 (3), 57-66 (1996)

36. M. Patterson, R. Elliott, Consumption, Markets and Culture, 5 (3), 231-246 (2002)

37. U. Hakala, Adam in Ads: A thirty-year look at mediated masculinities in advertising in Finland and the US (2006)

38. F. Mort, Cultures of Consumption. Masculinities and Social Space in Late TwentiethCentury Britain (1996) 